\section{A FILOSOFIA AFRICANA E \\ O PROJETO IDENTITÁRIO: \\ PERSPECTIVAS E DESAFIOS DA \\ EDUCAÇÃO NO CONTEXTO DA \\ GLOBALIZAÇÃO}

A Filosofia Africana e

o Projeto Identitário:

Perspectivas e Desafios da

Educação no Contexto

da Globalização

Gregório Adélio Mangana ${ }^{I}$

Anselmo Panse Chizenga ${ }^{2}$

\title{
Resumo
}

O presente artigo analisa o contexto e as metamorfoses da (re)produção do significado objetivo e subjetivo da África na filosofia e suas repercussões na afirmação das identidades africanas, tendo como foco a esfera educacional, sobre a qual incidem grandes indagaçóes sobre as perspectivas endógenas no contexto de globalização. A metodologia empregue foi a revisão bibliográfica por intermédio dos autores africanos e não africanos que debatem a temática da filosofia, identidade e educação africana. Pode-se perceber, a partir deste, que o processo da afirmação identitária repercute-se na esfera educacional - a qual está repleta de desafios e perspectivas, denominados de processos de marcha e contramarcha.

1 Professor de Filosofia na Universidade Pedagógica de Moçambique, Licenciado em Filosofia pela Universidade Pedagógica de Moçambique, Mestrando no programa de pós-graduaçáo em sociologia da Universidade Federal de Pernambuco-Brasil, membro do grupo de pesquisa Sociedade Brasileira Contemporânea: cultura, democracia e pensamento social da Universidade Federal de Pernambuco. Correio eletrónico: manganagregor@gmail.com

2 Licenciado em Filosofia pela Universidade Pedagógica de Moçambique. Estudante bolsista, PEC-PG/CNPq, do mestrado no Programa de PósGraduaçáo em Sociologia da Universidade Federal do Rio Grande do Sul, na linha de pesquisa Tecnologia, Meio Ambiente e Sociedade (TEMAS) e membro do da Rede Interdisciplinar e Multidisciplinar de Pesquisas (RIMPs) em Estudos Africanos, do Instituto Latino Americano de Estudos Avançados (ILEA-UFRGS).

Educ. Foco, Juiz de Fora, 
Palavras-chave: Filosofia. África. Educação.

\section{AFRICAN PHILOSOPHY AND IDENTITY PROJECT: PERSPECTIVES AND CHALLENGES OF EDUCATION IN THE GLOBALIZATION CONTEXT}

\section{Abstract}

This article analyzes the context and the metamorphoses of the (re)production of Africa's objective and subjective meaning in the philosophy and its impact on the assertion of African identities, focusing on the educational sphere, on which concern big questions about the endogenous perspectives in the context of globalization. The methodology employed was the literature review through African and non-African authors who discuss the theme of African philosophy, identity and education. It is possible to perceive, from this, that the process of identity affirmation reflects in the educational sphere, that is full of challenges and perspectives, and that we call play and counterplay processes.

Keywords: Philosophy. Africa. Education. 


\section{A FILOSOFIA AFRICANA E O PROJETO IDENTITÁRIO: PERSPECTIVAS E DESAFIOS DA EDUCAÇÁO NO CONTEXTO DA GLOBALIZAÇÃO}

\section{O GENITIVO "ÁFRICA” NA FILOSOFIA: (DES)MARCHAS DA FILOSOFIA AFRICANA}

\author{
Os africanos entram na "história universal" como \\ escravos, colonizados e hoje globalizados.
}

Severino Elias Ngoenha (2011)

Para falar de filosofia africana e sua relação com o processo de construção de identidade, é indispensável partirmos de duas categorias fundamentais no debate filosófico africano, nomeadamente: a concepção objetiva e a subjetiva, em torno da qual o significante "África" está em volta. De acordo com Dismas Masolo (1994, p. 1, tradução nossa),

A origem do debate filosófico africano está associada a dois principais eventos: o discurso ocidental sobre a África, e a resposta africana a essediscurso, no centro deste debate está a concepção da razão, valor que grandemente divide estados civilizados e não civilizados, $o$ lógico e o mítico [...] e [...] passando por dois campos: Ocidental e não ocidental ${ }^{3}$.

Afiguramos importante recorrer a este autor, não só pelo fato deste conceber que a particularidade da filosofia africana é a busca da identidade, mas pela distinção conceitual provida

3 "The birth of the debate African philosophy is associated with two related happenings: western discourse on Africa, and the African response to it... At the center of this debate is the concept of reason, a value which is believed to stand as the great divide between the civilized and the uncivilized, the logical and mystical... and... Passed between the two camps: western and nonwestern" (MASOLO, 1994, p. 1, transcrição original).
Educ. Foco, Juiz de Fora, 
de historicidade africana em dois âmbitos: primeiro, o discurso ocidental sobre a África (a África como objeto) e o segundo, intimamente vinculado à filosofia africana como reação dos africanos a objetividade ocidental. Essas gramáticas se resumem em dois genitivos específicos nos quais o significante "África" é a referência, o genitivo objetivo e o genitivo subjetivo. Se no primeiro o discurso filosófico é sobre África, em que o africano constitui objeto de produção ocidental, no último os africanos são eles próprios sujeitos do discurso filosófico, configurando um esforço endógeno de reflexão.

O primeiro momento, vinculado ao genitivo objetivo, pode ser caracterizado como momento de produção exótica da África, que consiste na negação da condição humana aos africanos. Aqui se dá a invenção de África como objeto do olhar e da interpretação alheia. Para legitimar essa concepção, as humanidades, em particular a filosofia, constituem um instrumento fundamental na produção e legitimação de gramáticas tendentes à inferiorização dos africanos, mobilizando um conjunto de variáveis como crença, pensamento, espaço e tipo de ser humano. É nesse sentido que se inserem as reflexóes de filósofos como Kant, Hegel e outros.

Kant (1724-1804), em sua obra, Observaçáo sobre o sentido do belo, ao estabelecer um conjunto de traços caraterísticos dos povos de diferentes nacionalidades europeias, refere-se aos africanos nos seguintes moldes:

Os negros da África não possuem, por natureza, nenhum sentimento que se eleve acima do ridículo. O senhor Hume desafia qualquer um a citar um único exemplo em que um negro tenha mostrado talentos, e afirma: dentre os milhóes de pretos que foram deportados de seus países, não obstante muitos deles terem sido postos em liberdade, não se encontrou um único sequer que apresentasse algo grandioso na arte ou na ciência, ou em qualquer outra aptidão; já entre os brancos, constantemente arrojam-se aqueles que, saídos da plebe mais baixa, adquirem 
no mundo certo prestígio, por força de dons excelentes. Tão essencial é a diferença entre essas duas raças humanas, que parece ser tão grande em relação às capacidades mentais quanto à diferença de cores. A religião do fetiche, tão difundida entre eles, talvez seja uma espécie de idolatria, que se aprofunda tanto no ridículo quanto parece possível à natureza humana. A pluma de um pássaro, o chifre de uma vaca, uma concha, ou qualquer outra coisa ordinária, tão logo seja consagrada por algumas palavras, tornam-se objeto de adoração e invocação nos esconjuros. Os negros são muito vaidosos, mas à sua própria maneira, e tão matraqueadores, que se deve dispersá-los a pauladas (KANT, 1993, p. 75-76).

Para Kant, as dinâmicas socioculturais no continente africano se resumiam no caráter bizarro dos negros. $\mathrm{O}$ mesmo percurso será trilhado por Hegel (1770-1831), para quem o que constitui a essência do ser africano é o constrangimento a que a África está mergulhada, desde a sua configuração geográfica até as diferenças de carácter espiritual. $\mathrm{O}$ caráter da África é adverso à cultura e a realidades europeias, daí o africano será definido como oposto ao valorativo, sem religião, estado, lei moral e eticidade: "o negro representa o homem natural em toda a sua selvajaria e barbárie, se pretendemos conhecê-lo devemos deixar de lado todas as representaçôes europeias" (HEGEL, 1995, p. 180).

É devido a uma característica comum de ausência de axiologia humana e empobrecimento antropológico que "a escravatura constitui a relação jurídica fundamental", na medida em que conduziu este grupo social à consciência de liberdade que eles próprios passaram a disputar (HEGEL, 1995, p. 187).

$\mathrm{Na}$ visão de Hegel, a África não é única, mas dividida em três partes distintas e cada uma sem qualquer relação com a outra: uma é a que se situa ao norte do deserto, a África
A Filosofia Africana e o Projeto Identitário: Perspectivas e Desafios da Educação no Contexto da Globalização
Educ. Foco, Juiz de Fora, 773 v. 21, n.3, p. $769-792$ 
europeia, no dizer de Hegel, que inclui atuais territórios de Marrocos, Argel, Túnis, Trípoli, toda esta parte não pertence à África, mas sim à Espanha e é por isso que ela partilha o destino dos grandes, que é decidido em outras partes; a segunda seria a região fluvial do Nilo, o único vale da África que se une à Ásia, a região que se estende até o Egito; por último, encontramos a "África propriamente dita", que se situa ao sul do Saara, a que constitui a parte característica deste continente, razáo pela qual todas as adjetivaçóes antes apresentadas confinam-se a uma região específica.

A partir dos enunciados acima, observa-se que o primeiro momento de aparição filosófica da África e dos africanos é a afirmação de uma identidade e alteridade africana, uma produção exógena toldada de pressupostos eurocêntricos e racistas em voga. Isso náo surpreende, tendo em conta as circunstâncias históricas, o panorama ideológico e intelectual da época moderna: o evolucionismo, o racismo e a pretensão de transformar a humanidade para fins ideológicos. E é esse o espírito da colonizaçáo, escravatura e racismo que as posiçóes anteriores são bastante esclarecedoras.

Como observa Mveng (1999), essa concepção é o corolário "pauperização antropológica" ligada à invenção de categorias sociais tendentes à coisificação do outro, com base nos estereótipos como localização geográfica, traços socioculturais em uma escala hierárquica de valores (na qual os africanos se encontram em posiçóes inferiores). Portanto, a ciência e a religião viram-se para legitimar o ideal expansionista, negando a humanidade do africano.

O sociólogo francês Wieviorka (1998, p. 170) entende que esses fatos tinham por objetivo

a destruição dos que parecem constituir um obstáculo económico, político e cultural à progressão do homem branco; a dominação dos outros, necessariamente subordinados em nome da raça, seja elas populaçóes autóctones 
[...] ou populaçóes deslocadas no quadro da escravatura.

Em seguida do processo de produçáo acadêmica de matriz eurocentrista, na qual a filosofia africana figura como "objeto" de miragem alheia, inicia-se o segundo momento no qual, segundo Masolo (1994), é da resposta ou réplica africana ao discurso sobre a África. Este momento é caraterizado como o da construção endógena, em que os próprios africanos procuram assumir as rédeas da produção intelectual, configurando, deste modo, o momento da subjetivação e intersubjetivação, ou seja, o da colocaçáo do próprio africano no centro e como sujeito do discurso intelectual.

Para efeitos didáticos, podemos afirmar que os momentos da produção filosófica e constituição das identidades endógenas africana são abrangidos por seis grupos divergentes em termos de conteúdo semântico de suas reflexôes filosóficas: a diáspora e a vertente política; a escola etnológica; a escola crítica; a escola crítica da crítica; a escola hermenêutica; a escola autonomistaintersubjetivista.

De forma sucinta, destacaremos aquilo que foi o principal conteúdo de três perspectivas da filosofia africana. Não obstante a diferença epistemológica substancial entre distintas correntes, o grosso modo dessas incursóes converge na materialização do esforço endógeno fundada na cultura e valores "eminentemente" africanos, envolvendo um conjunto de operaçôes críticas (discursos e açôes), mobilizando conceitos (dos quais a razáo), referencial teórico, objeto empírico e metodologias específicas, de modo a afirmar a identidade africana na marcha existencial com base em repertórios e experiências vivenciadas que orientam suas cosmovisões - é o momento da construção "reinvenção da África", inaugurando um debate em torno das identidades africanas.

No que tange à escola etnológica, a partir da segunda metade do século XX, sobretudo na década de 1970, iniciamse a produção intelectual e um debate de ideias variadíssimo,
A Filosofia Africana e o Projeto Identitário: Perspectivas e Desafios da Educação no Contexto da Globalização
Educ. Foco, Juiz de Fora, 775 s.21, n.3, p. $769-792$, 
com posiçóes contraditórias e abordagens polêmicas entre os teóricos africanos. O âmbito do debate gira em torno da possibilidade de se fazer filosofia no contexto africano, tendo em conta a especificidade de tradiçóes, culturas, contos e lendas.

Para Ngoma Binda (1982 apud NGOENHA, 2014), a publicação em 1945 da obra La philosophie Bantu, do missionário belga Placide Tempels (1906-1977), marca a gênese do debate filosófico ${ }^{4}$ escrito. Nesta obra, o autor procura se contrapor a Lévy-Bruhl, segundo o qual a filosofia bantu era pré-lógica (para Tempels, a filosofia bantu deve ser percebida como lógica, mas com uma lógica menor, apegada à sua ontologia com um sistema de princípios e um conjunto de ideias do homem, das coisas que o circundam, da existência, da vida, da morte e da vivência). Ou seja, o sistema ontológico negro já foi elaborado há tempos, mas escapa ao pensamento dos bantu, adverte o autor, para quem

Não pretendemos reivindicar que os Bantus são capazes de formular um sistema filosófico acabado com um vocabulário adequado. Nosso objetivo é desenvolver e sistematizar esse pensamento. É graças a nossa própria preparação intelectual que ele irá sendo desenvolvido de forma sistemática. Cabe-nos fornecer-lhes um quadro preciso de concepçóes das entidades de forma a que eles se reconheçam nas nossas palavras e concordem dizendo: Vós percebestes-nos, agora conhecei-nos completamente, "conheceis" da mesma forma

4 Uma análise detalhada sobre o porquê em torno da filosofia africana, mais do que qualquer outra disciplina das ciências humanas, cf. Appiah (1996); Hountondji (2010) e a monografia cientifica intitulada Os desafios da filosofia africana na construçáo das identidades africanas em Kwame Anthony Appiah, de Chizenga (2011). 
que nós conhecemos (TEMPLES, 2006, p. 17, tradução nossa). ${ }^{5}$

Uma das repercussóes do trabalho de Tempels é a aparição de um conjunto de trabalhos científicos - teses, dissertaçóes, artigos, obras, entre outros de autores africanos contestando ou seguindo a mesma direção, marcando assim distintas correntes cujo eixo de reflexão ou prescrição normativa das formas de produçáo intelectual africana e seu conteúdo.

$\mathrm{Na}$ senda de Tempels, outros autores seguiram a mesma abordagem: descrever/ reconstruir apenas a cosmovisão dos seus antepassados e os pressupostos coletivos das suas tradições. Os mais destacados destes foram Alexis Kagame, em seu trabalho A filosofia bantu-ruandeza do ser, e John Mbiti. Em seus trabalhos, estes autores referem que a essência africanidade e da possibilidade da sua cientificidade reside nas suas línguas, tradiçôes, contos, lendas, religião. Ou seja, advogam em torno duma ontologia eminentemente africana. Segundo os críticos, esses autores empreenderam esforços regressivos, pois fazem uma filosofia sem filósofos, ou seja, centrada na visão coletiva e irrefletida do mundo.

Contrapondo-se à perspectiva etnográfica, a primeira geração da escola crítica é marcada por figuras como Crahay, Hountondji ${ }^{6}$, Wiredu e Eboussi Boulaga. Em suas incursóes, estes autores questionam o substrato epistemológico de uma ontologia africana, por meio da oralidade e do pensamento coletivo na produção do saber científico: até que ponto os

5 Versão original: "We do notclaim, of course, that the Bantu are capable of formulating a philosophic altreatise, complete with in adequate vocabulary. It is our job to proceed to such systematic development. It is we ho will be able to tell them, in precise terms, what they're in most concept of beingis. They will recognize them selves in our word sand will acquiesce, saying, "You understand us: you now know us completely: you "know" in the way we know".

6 Hountondji abandonou esta perspectiva ao longo da sua carreira. Cf. SANTOS; MENEZES (org.). Conhecimento de África, Conhecimento de africanos: duas perspectivas sobre os estudos africanos. Coimbra: Contraponto, 2009. p. 119-132. Cf. CASTIANO. Referenciais da filosofia africana: em busca da intersubjectivação. 1. ed. Maputo: Ndira, 2010.
A Filosofia Africana o Projeto Identitário: Perspectivas e Desafios da Educação no Contexto da Globalização

Educ. Foco, Juiz de Fora, $777^{\text {v. } 21, \text { n.3, p. 769-792 }}$ set. / dez. 2016 
saberes locais, os contos, as lendas transmitidas oralmente são dignos de um tratamento científico, até que ponto a tradição oral e seus dogmatismos servem na consolidação do saber científico prementes na oralidade? Isso significa dizer que, para estes autores, não há produção científica onde domina a cultura oral e um horizonte histórico voltado para o passado, problematizando deste modo o papel das tradiçóes na produção do saber.

A definição da filosofia africana como um conjunto de texto serve para prevenir que elementos da tradiçáo oral servem como ponto de referência da especulação filosófica, ou seja, "trata-se de demonstrar que os nossos contos morais, as nossas lendas didáticas, os aforismos, os nossos provérbios, aos quais normalmente se faz referência, não exprimem uma investigação" (NGOENHA, 2014, p. 98).

Segundo Elisio Macamo (1998), as respostas à invenção de África acabam sendo ela mesma o arcabouço teórico da produção intelectual na qual os acadêmicos africanos são levados a assumir responsabilidades intelectuais próprias, em um contexto plural, tendo noção das contradiçóes, dos debates internos e das tensóes intelectuais que retroalimentam a produção cientifica no continente.

Este momento, longe de constituir consenso entre filósofos africanos, constitui um problema filosófico, pois está em volta de debates e posições polêmicas internas, o que sob o ponto de vista de debate de ideias é interessante, mas analisando a agenda e as circunstâncias em que são produzidas e continuam sendo produzidas até hoje é bastante complexo. Isso pois os intelectuais, longe de produzirem e proporem desafios e alternativas teóricas e empíricas, tendem a viciar sua produção intelectual com distorçôes e ficçôes sobre a África introduzidas pelos teóricos ocidentais a influência dos próprios cientistas que, nas suas análises, reproduzem e usam categorias essencializadas, mesmo de forma inintencional, o que se repercute no processo de educaçáo com valores e perspectivas identitária endógenas (MUDIMBE, 1989; APPIAH, 1996). 


\section{DEBATE SOBRE IDENTIDADE E SUAS REPERCUSSÓES NA ESFERA EDUCACIONAL}

O debate em torno das identidades africanas assume diferentes perspectivas e sentidos distintos. Geralmente, fala-se de identidades africanas quando se pretende ajuizar de como a vida social e orgânica da África foi influenciada pelo desenvolvimento econômico, industrial e social da colonização e influências socioculturais de outros povos (CHIZENGA, 2011).

Nestes moldes, o discurso sobre as identidades africanas toma a dianteira, na medida em que o continente, como uma invenção da ciência do século XIV-XIX, estava destinado a servir os seus "predadores" em nome da superioridade racional e racial dos navegadores europeus em relaçáo aos autóctones.

O processo de construção e afirmação das identidades africanas visava desconstruir o mito da inferioridade dos africanos evocando uma série de categorias e valores endógenos - raça, cultura e cosmologias - de modo a promover a sua afirmaçáo, exaltando uma releitura do passado visando estimular o significado e a essência de ser africano em um mundo marcado pelo pluriculturalismo, multiracismo e, acima de tudo, pelo diálogo intercultural.

Appiah (1997, p. 242-243) define identidade como a "coalescência de estados de conduta, hábitos de pensamentos e padróes de avaliação mutuamente correspondentes". Esta definição, a priori, evidencia a identidade como estando associada ao "mesmo". Nesta ordem de ideias, a identidade nos remete a um conjunto de atributos e qualidades fixas partilhadas pelos membros do mesmo grupo. Entretanto, a identidade, além de remeter para aquilo que é idêntico, também o faz para o que é distinto, a diferença em relação às outras identidades, distinguindo-se uma qualidade idêntica e específica da alterna - qualidade do outro.

Náo se pode falar de identidade social sem inteiraçáo social, processo pelo qual os indivíduos adquirem traços
A Filosofia Africana e

o Projeto Identitário:

Perspectivas e Desafios da

Educação no Contexto

da Globalização
Educ. Foco,

Juiz de Fora, 
distintivos que são específicos à sociedade em que foram criados, o que constituirá certa forma de identificação com base nos domínios culturais, geográficos, políticos e sociais que contribuem para a solidificação da identidade como grupo ou traços de referência nas relaçóes humanas, pois "a identidade é um modo historicizado e dinâmico de categorização simbólica usada por indivíduos e grupos nas suas trocas sociais" (SERRA, 1998, p. 10).

Além do território e de outros recursos de identificação, Liesegang (1998) refere que as semelhanças, como características naturais e experiências adquiridas, fundamentam as identidades. Com base em atributos e semelhanças partilhadas, encontramos dois âmbitos de identificação: a autoidentificação e a exoidentificação. Portanto, o premente no processo de construção das identidades africanas é a autoidentificação.

\section{A DIÁSPORA E A VERTENTE POLÍTICA NA CONSTRUÇÁO DE UMA IDENTIDADE NEGRO AFRICANA}

Um dos elementos agregadores de mobilização em torno das identidades africana tomou uma matriz racista, a partir da suposição da identidade negro africana. Essa afirmação identitária se difundiu na diáspora. A construção de uma identidade negro africana, além de ser uma legítima luta contra a alienaçáo cultural ${ }^{7}$, figura como uma tentativa de autorreabilitação e de assumir uma cultura africana perante a negação axiológica.

Os vínculos identitários avançados por esses autores têm a ver com o que supunham ser um destino comum aos povos da África. E esse destino provinha não pelo fato de partilharem um território, mesma experiência histórica ou enfrentarem

7 Para Fanon (1961), o colonialismo e a escravatura se propunham a arrancar os negros da noite e libertá-los da barbárie, aviltamento e animalização, o que ao invés de fazerem-no, perpetuaram-no. 
todos os ameaça da Europa imperialista, mas sim por serem todos negros e a África ser a sua pátria.

Para esses autores, era indiscutível que

as raças têm uma individualidade. Esta individualidade está sujeita, em todas as épocas, às leis da vida racial. Essa vida racial, em todo o globo, mostra uma invariável propensão, na totalidade dos casos, à integração do sangue $\mathrm{e}$ à permanência da essência (DU BOIS, 1964 apud APPIAH, 1997, p. 29).

A concepção de uma identidade africana com base na raça deve-se ao fato de a raça, em relação a outros vínculos componentes identitários, não ser manipulável, pois apesar da inteiração e dinamismos social em que os elementos identitários possam ser negociáveis e confundidos, no caráter biológico de diferença racial permanece a essência, ou seja, o conteúdo e o valor da raça permanecem constantes. Para esses autores, a afirmação da personalidade africana com base na raça emerge como uma força estimuladora para a exaltação do ser negro como uma perspectiva na edificação de uma nova sociedade não alicerçada no passado, mas voltada para o futuro. Esta era uma forma enérgica de emergir e de se afirmar na convivência universal.

Há quem diga que esses pensadores tinham, apesar das elevadas esperanças em relação aos negros, opiniôes muito negativas a respeito de suas línguas, religião e cultura africanas, portanto não é de admirar que, em face da tentativa de se afirmar como africanos, também se achavam mais civilizados e desejavam civilizar a África e os negros continentais (APPIAH, 1997).

Alguns consideram que, por obrigaçóes históricas, os pensadores e idealizadores das identidades africanas tiveram que racializar as suas reivindicaçóes, pois, mais do que nunca, era preciso regressar às raízes para evitar mutilaçóes psicoefetivas extremamente graves. A concepção de uma identidade negro
A Filosofia Africana o Projeto Identitário: Perspectivas e Desafios da Educação no Contexto da Globalização
Educ. Foco, Juiz de Fora, v. 21, n.3, p. $769-792$ set. / dez. 2016 
africana emerge como uma força enérgica de criatividade interior, face ao desconforto da exclusão social e das amarguras da descriminação racial por eles vivenciados.

No que diz respeito à diáspora africana e a perspectiva política, movimentos emancipatórios organizados por afrodescendentes na América do Norte, e a primeira geração de intelectuais africanos, formada nas academias ocidentais instruídos com base nas teorias etnocêntricas do Ocidente, empreenderam um esforço no sentido de se emancipar das objeçóes falaciosas nas quais eles eram referenciados ${ }^{8}$ marcando, assim, o primeiro esforço endógeno.

Uma passagem rápida dos principais teóricos afrodescendentes do século XX, cujas reflexóes orientaram para uma matriz identitária e a personalidade africana, para estes a "raça" e a suposição de origem geográfica constituíam um elemento agregador de mobilização social: é com base na "raça" que esses grupos se organizam e reclamam o devido reconhecimento.

Nesta perspectiva, destacam-se figuras como Alexander Krummel (1819-1898), Booker Washington (1856-1915), Edward Blynden (1832-1912), Marcus Garvey (1887-1940), e W. E. B. Dubois (1868-1963); outro grupo de afrodescendentes e intelectuais africanos de primeira geração formados na diáspora, que se ocuparam da questão político, são: Joseph B. Danquah (1895-1965), Kwame Nkrumah (1909-1972), Léopold Senghor (1906-2001), Aimée Césaire (1913-2008), Frantz Fanon (1925-1961), Julius Nyerere (1922-1999), entre outros. Estes pensadores, com um cunho pan-africano e nacionalista, constituem os primeiros esforços de produção intelectual africano (HALLEN, 2001; MACEDO, 2014).

8 O erudito ganês Kwasi Wiredu conta em uma das suas obras ter ficado surpreso ao perceber, em idade e formação avançada, tempos depois, o significado e o alcance real das teorias em fora instruído as pejoraçôes sobre os africanos que dominavam, daí começou a dedicar grande parte de suas reflexóes para descontruir a concepçáo que lhe ajudaram a construir sobre si. 


\section{FILOSOFIA E IDENTIDADE AFRICANA: UMA PERSPECTIVA EDUCACIONAL}

Não nos parece fácil falar sobre identidades africanas sem fazer menção às questóes fundamentais que sustentam esse debate, os contextos históricos sociais e os desafios específicos em que elas visavam responder, coadjuvada a noção de africanidade e experiências concretas que os africanos partilham e acreditam ser a essência da africanidade.

Segundo refere Liesegang (1998, p. 119), "procura-se identidade para adquirir uma maior dignidade, mas também para normalizar uma situação considerada anormal [...]. A recuperação de uma tradição talvez seja uma maneira de ocupar um espaço maior numa sociedade multicultural”.

A reflexão avançada por Liesegang afigura-se essencial para percebermos a temática e a razão de ser de algumas identidades que hoje reclamam seu espaço, e a nossa reflexão o faz no âmbito do debate sobre as identidades africanas, nas quais, na sua territorialidade e perante os poderes dominantes, lutam por se desidentificar como identidades subalternas que lhes foram impostas pelos poderes exógenos que a dominaram e hoje sob forma de desenvolvimento e globalização tomam a dianteira (CHIZENGA, 2011).

Sobre as identidades africanas e as questóes do seu surgimento, o filosofo queniano Dismas Masolo afirma:

Por razóes óbvias, um dos temas dominante na teoria pós-colonial é a temática sobre as identidades, nas suas diversas e variadas formas [...]. Isto se justifica devido a ocorrências coloniais e o seu impacto histórico, político e cultural nas sociedades que durante séculos de décadas sucumbiram na dominação colonial, e compreenderam as implicaçôes significativas
A Filosofia Africana e

o Projeto Identitário:

Perspectivas e Desafios da

Educação no Contexto

da Globalização
Educ. Foco,

Juiz de Fora, 783 v.21, n.3, p. 769-792 
de se libertarem desta dominação9 (MASOLO, 1997, p. 283, tradução nossa).

Com base nessa afirmação, é evidente que a temática identitária que atravessa largamente a literatura africana é uma reação ao domínio colonial. Assim, para perceber o atual projeto da África, é indispensável partirmos do impacto do desenvolvimento da Europa na época moderna. É nesta época que se inicia a colonização e exploração legal, em nome da razão vinculada à ideia de "povos" superiores e inferiores, como motor de desenvolvimento econômico das sociedades capitalistas - a venda de pessoas e força de trabalho -.

Para tal, havia os destinados a serem objetos de tal desenvolvimento, pois, segundo as teorias racistas e eurocentristas dominantes, os não ocidentais - para fazer menção aos países centrais da Europa e a América do Norte tinham uma deficiência de capacidades morais e intelectuais. É isso que fundamentava uma desigualdade natural entre os homens.

\section{SABERES ENDÓGENOS NA EDUCAÇÃO CONTEMPORÂNEA AFRICANA}

O debate sobre a educação em África nos leva à partida, às peripécias da colonização africana e às perspectivas póscoloniais em prole da valorização, preservação das culturas e identidades africanas, por um lado, e por outro, aos ditames em prole da legitimação dos saberes ditos locais ou endógenos e a sua integraçáo nos distintos programas de ensino ou currículos específicos em escolas e universidades. Esse debate perpassa perspectivas controvérsias entre o dito tradicional e o moderno.

9 "For quite good reasons, one of the dominant themes of postcolonial theory is the issue of "identity", in most if not all its various forms [...]. Its justification lies in the very heart of historical occurrence of colonialism and its political and cultural impact on those societies which perceived many centuries and decades under colonial domination and in the perceived meaning and implications of the removal of this domination." 
Em qualquer temporalidade histórica as sociedades são incitadas a pensar, e o que os motiva a tal situação é sempre o encontro traumático, violento, com uma realidade externa que se impóe brutalmente, colocando em causa as suas formas rotineiras de pensar (ZIZEK, 2006). A situação em África, concernente a grandes reflexões sobre a educação, não foi diferente. O que leva os intelectuais a cogitar no status quo da educação em África é a facilidade de influências externas que afetam o seu espaço geográfico e que póem em causa os seus diversos sistemas de conhecimento.

Os debates sobre a educação em África apresentam posiçôes paradigmáticas conflitantes. Algumas são apologistas na eliminaçâo do velho pelo novo (na eliminaçáo de todos os desígnios da tradição africana), umas com uma posição oposta a esta (na eliminação de tudo que é estranho a africana), e outras, mais moderadas, são apologistas na articulação conjunta, do que é essencialmente africano e do que é externo à África.

Os argumentos são vários, os primeiros alegam que o africano tem que se desfazer da sua tradiçáo, porque esta faz com que se atrase na entrada ao mundo globalizado; os segundos acreditam que toda a riqueza ou legado da tradição é a essência do africano e da África, daí a importância da sua valorização; os últimos tentam unir os dois tecidos, defendendo maior riqueza do terreno educacional africano ao fazer dialogar as diversas formas de conhecimento.

O debate entre o tradicional e o moderno tem ganhado grande interesse por parte dos intelectuais africanos. A grande inquietação é se as nossas tradiçóes devem, de fato, se tornarem modernas e essa realidade vem se manifestando com muita intensidade no campo de educação. Entretanto, a questão em si é polêmica, pois, como nos assegura o filósofo ganês Kwame Gyekye (1997), do ponto de vista da essência e do fundamento da tradiçáo, podemos dizer que toda a sociedade em nosso mundo moderno é tradicional quando ela abona os
A Filosofia Africana e o Projeto Identitário: Perspectivas e Desafios da Educação no Contexto da Globalização
Educ. Foco, Juiz de Fora, $785^{\text {v. } 21, \text { n.3. p. } 769-792}$ 
valores, as práticas, as perspectivas e as normas legadas pelas geraçóes anteriores.

O facto de que toda sociedade no mundo moderno herda valores culturais ancestrais, implica que a modernidade nem sempre é uma rejeição do passado. Diante disso, é crucial desmistificar todo o discurso que apela a tradição como algo de África e de africanos e a modernidade como sendo algo do ocidente. É importante ainda frisar que, mesmo em tais ditas "sociedades tradicionais", tem uma proporção de crenças e práticas herdadas do passado.

No entanto, essa mesma sociedade verifica uma variedade de experiências de mudanças ao longo do tempo, isto é, não é estática e inalterável. Isso porque valores culturais, crenças e normas legadas por uma geraçáo podem ser rejeitados e repudiados por uma geração posterior. Como refere Gyekye (1997), as tradições não são inconciliáveis com a modernidade eliminando-se, desse modo, a percepção de oposição entre a tradição e a modernidade.

Para Gyekye, algumas características da modernidade ocidental podem náo ser apropriadas para as sociedades e culturas africanas e talvez para outras culturas não ocidentais. Pensadores como Stuart Hall, Hountondji, Masolo, Sousa Santos, entre outros, já alertavam sobre este fato. Hall (1997, p. 3), por exemplo, refere que

Há, certamente, muitas consequências negativas [...] em termos das exportaçóes culturais do ocidente tecnologicamente superdesenvolvido, enfraquecendo e minando as capacidades de naçóes mais antigas e de sociedades emergentes na definição de seus próprios modos de vida e do ritmo e direção de seu desenvolvimento.

Os saberes endógeno, mesmos que tenham sobrevivido os povos que os detém, eles precisam doravante que sejam resgatados porque encontram-se ainda subalternizados 
em nossas sociedades. É necessário, como dizem Gyekye e Hountondji, apropriá-los. Como sugere Hountondji (2006), antes de ser bem aplicado, o conhecimento tradicional deveria ser testado constantemente pelas pessoas, as quais deviam reapropriá-lo para que torne possível a sua ligação indispensável com o avanço da ciência e da tecnologia. É preciso ajudar as pessoas na administração e na capitalização do conhecimento endógeno.

Os saberes que são legados pelas sociedades servem como um vínculo de orientaçáo para o seu povo, quer de forma coletiva ou individual. Este facto se reflete como um retrato à temporalidade histórica africana, mesmo em termos de busca de um ideal educacional, é sabido que as experiências póscoloniais dos povos africanos são em grande parte comuns.

De acordo com Masolo (2006), os elementos que constituem ou determinam a personalidade de um indivíduo são acreditados no seu meio sócio-ontológico. Para este autor, na educação tradicional africana, as crianças, por exemplo, eram treinadas para levar mensagens entre aldeias aos parentes e amigos da família. Esse ato era bastante benéfico no aprendizado e desenvolvimento de outras habilidades sociais para as crianças, pois incutia a elas virtudes de obediências e serviços mútuos e, sobretudo, a capacidade de ouvir atentamente, compreender, lembrar e precisamente transmitir mensagens verbais. A educaçáo moral, por exemplo, que era adquirida nos ritos de iniciação, um pouco por todas as sociedades africanas, e a educação cultural que se dava na maioria das sociedades africanas, em um período de reclusão na floresta, proporcionava na pessoa fundamentos éticos e o ideal do bem comum.

Os debates filosóficos contemporâneos sobre a legitimação dos saberes endógenos nas escolas e universidades ocupam em grande parte as mentes de intelectuais africanos. Castiano, em seu trabalho Os saberes locais na Academia: condiçóes e possibilidades da sua legitimaçáo (2013), trás um discurso de preservação e valorização, abrindo o horizonte para que
A Filosofia Africana e o Projeto Identitário: Perspectivas e Desafios da Educação no Contexto da Globalização
Educ. Foco, Juiz de Fora, $787^{\text {v. } 21, \text { n. } 3, \text { p. } 769-792}$ 
estes saberes tenham o devido espaço nos círculos acadêmicos e nos programas de ensino em escolas e universidades.

Segundo Castiano (2013), é comum em grande parte de filósofos profissionais africanos a atitude de rejeição em integrar/considerar os saberes locais/endógenos ao nível das academias/universidades. De acordo com esta abordagem, há um esforço sobretudo de filósofos profissionais africanos contemporâneos em trazer e legitimar os saberes endógenos nas universidades.

A rejeição, acreditamos, é geralmente, fundamentada e alimentada pelas entidades que estão à frente das definições de políticas educativas. Aliás, o próprio Castiano (2013) reconhece que os filósofos profissionais concordam sobre o papel das tradiçóes e do conhecimento endógeno em relação ao futuro da África.

A crítica, que pode levar a um doravante debate sobre o saber endógeno nas escolas e na universidade, deve ser realizada e direcionada às entidades definidoras de políticas educativas e aí os filósofos têm um grande papel. Todavia, temos que concordar com Castiano (2013) a respeito da necessidade de legitimação dos saberes endógenos no contexto das academias africanas e, para este autor, a legitimação só poderá se efetivar por meio de um diálogo entre sujeitos epistémicos (intersubjetivos).

O futuro da África se resume, efetivamente, na motivação em apreendermos de forma substancial os nossos conhecimentos. Os nossos paradigmas epistemológicos precisam de ser salvaguardados, todavia, vale frisar que esta reivindicação, dos saberes endógenos, não significa a rejeição dos outros tipos de saberes, mas sim a sua valorização pela sua utilidade social. Desta forma, podemos dizer que os diferentes tipos de saber podem partilhar o mesmo espaço e dialogarem, circundante, identificando e reconhecendo, entre eles, seus limites e possibilidades (MANGANA, 2014). 
A questão que se coloca na África hoje já não é entre a africanização e a ocidentalizaçáo (posta por pensadores ao longo da história africana, como Horton, Blyden, Carr etc.) e nem o dilema segundo o qual devemos ou não levar os nossos filhos à nova escola, a estrangeira, o qual Kane aborda no seu romance A Aventura Ambígua.

A educação contemporânea africana em tempos atuais impera por um diálogo entre realidades epistemológicas diversas, a fim de buscar valorizar os diferentes sistemas de conhecimento existentes no mundo.

\section{REFERÊNCIAS}

CASTIANO, J. P. Referenciais da filosofia africana: em busca da intersubjectivação. 1. ed. Maputo: Ndira, 2010.

. Os saberes locais na Academia: condiçóes e possibilidades de sua legitimação. CEMEC: Universidade Pedagógica, Maputo, 2013.

CHIZENGA, A. P. Os desafios da filosofia africana na construçáo das identidades africanas em Kwame Anthony Appiah. (Monografia cientifica). Maputo: Universidade Pedagógica, 2011.

ESCOBAR, A. Más allá del tercer mundo: globalización y diferencia. Bogotá: s./ed., 2005.

GYEKYE, K. Tradition and modernity: philosophical reflections on the African experience. New York: Oxford University Press, 1997.

HALLEN, B. A short history of African philosophy. USA: Indiana University Press, 2002.

HOUNTONDJI. P. Conhecimento de África, conhecimento de africanos: duas perspectivas sobre os estudos africanos. In: SANTOS, B. de S.; MENESES, M. P. (org.). Epiatemologias do Sul, Almedina, Coimbra, 2009, p. 119-132.

KANE, C. H. Aventura ambígua. São Paulo: Ática, 1984.

KANT, I. Observaçóes sobre o sentimento do belo e do sublime. Campinas: Papirus, 1993.
A Filosofia Africana o Projeto Identitário: Perspectivas e Desafios da Educação no Contexto da Globalização
Educ. Foco, Juiz de Fora, 
MACAMO, E. A influência da religião na formação de identidades sociais no sul de Moçambique. In: SERRA, C. (dir.). Identidade, moçambicanidade, moçambicanizaçáo. v. I. Maputo: Livraria Universitária, 1998. p. 35-69.

MANGANA, G. A. Paradigmas socioculturais, educação e desenvolvimento em Moçambique: uma perspectiva socioepistemológica. In: DUARTE, S. M. et al. (org.). As ciências sociais e humanas: debate teórico-prático em Moçambique. Maputo: Escolar, 2014. p. 15-22.

MASOLO, D. A. African philosophy in search of identity. 1. ed. USA: Indiana University Press, 1994.

. Western and African communitarianism: a comparison. In: WIREDU, K. (ed.) A companion to African philosophy. Oxford: Blackwell Publishing, 2006.

- Filosofia e conhecimento indígena: uma perspectiva africana. In: SANTOS, B. de S.; MENESES, M. P. (org.): Epistemologias do sul. São Paulo: Cortez, 2010.

MBITI, J. African religions and philosophy. New York: Anchor Books, Doubleday \& Company, 1970.

MUDIMBE, V. Y. The invention of Africa: gnose, philosophy and other knowledje. Bloomington: Indiana Press University, 1988.

NGOENHA, S. E.; CASTIANO, J. P. Pensamento engajado: ensaios sobre filosofia africana, educação e cultura política. Maputo: Educar, 2011.

Filosofia africana: das independências às liberdades. 2. ed. Maputo: Paulinas, 2014.

O retorno do bom selvagem: uma perspectiva filosófica africana do problema ecológico. Porto: Salesianas, 1994.

RAMOSE, M. Globalização e ubuntu. In: SANTOS, B. de S. (org). Epistemologias do sul. Coimbra: Almedina, 2009. p. 135-176.

SANTOS, B. de S. A gramática do tempo, para uma nova cultura política. 3. ed. São Paulo: Cortez, 2013.

TEMPELS, P. Bantu philosophy. Honoré: Vinck, 2006. 
WIEVIORKA, M. A nova era do racismo: racismo, etnicidade e poder. In: SERRA, C. (dir.). Identidade, moçambicanidade, moçambicanização. v. I. Maputo: Livraria Universitária, 1998. p. 169-194.

ŽIŽEK, S. A subjectividade por vir: ensaio crítico sobre a voz obscena. Lisboa: Relógio D’Água, 2006.

Submetido em:16/ 08/ 2016

Aprovado em: 10/ 09/ 2016 